\section{Floral Initiation and Development in Sisyrinchium bermudiana}

\author{
G.L. Roberts, M.J. Tsujita, and J. Gerrath \\ Department of Horticulture, University of Guelph, Guelph, Ont. \\ N1 G2 Wl, Canada
}

Additional index words. blue-eye grass, scanning electron microscopy

\begin{abstract}
Sisyrinchium bemudiana L. plants were grown in growth chambers under lo-hour short-day regimes. Scanning electron microscopy of shoot apices collected at biweekly intervals showed that the transition from vegetative to floral status occurs after 10 weeks of short days. Stamens and tepals develop first as common stamentepal primordia that then bifurcate to form outer tepals with stamens opposite. Subsequently, the inner tepals are initiated in an alternate pattern.
\end{abstract}

Previous studies have shown that floral induction in Sisyrinchium bermudiana occurs after a short-day (SD) inductive cycle of at least 8 weeks (Roberts, 1990a).

The objective of this experiment was to confirm floral initiation microscopically and document the early stages of floral development. This is the first report on the details of floral initiation and development in the genus Sisyrinchium. (Voucher specimen on file in Univ. of Guelph Herbarium, Acc. no. OAC74253). We will use the terminology of Holm (1908).

Sisyrinchium bermudiana seeds were leached and planted as described by Roberts (1990a) and placed into EY8VH growth chambers (Controlled Environments, Winnipeg, Manitoba) set at 14-h long days (LD) (350 $\mu \mathrm{mol} \cdot \mathrm{m}^{-2} \cdot \mathrm{s}^{-1}$ photosynthetic photon flux) and $16 \pm 2 \mathrm{C} / 21 \pm 2 \mathrm{C}$ (day/night). After 3 weeks of growth in LD, the seedlings were transferred to SD regimes. Fifteen samples of the treated plants were collected biweekly. The apices were dissected in $(1$ $\left.\mathrm{K} \mathrm{H}_{2} \mathrm{P} \mathrm{O}_{4} \cdot 2 \mathrm{H}_{2} \mathrm{O}: 1 \quad \mathrm{Na}_{2} \mathrm{HPO}_{4} \cdot \mathrm{H}_{2} \mathrm{O}\right)$ phosphate buffer ( $\mathrm{pH} 6.8)$ and fixed in $2 \%$ glutaraldehyde in phosphate buffer for $\approx 24 \mathrm{~h}$ (Hayat, 1981) [plants 11 weeks and older were fixed in formalin-acetic acid-alcohol, dissected, and stained with $0.5 \%$ alcoholic acid fuchsin (Posluszny et al., 1980)]. They were then postfixed in $2.5 \%$ osmium tetroxide for $2 \mathrm{~h}$ and dehydrated through a graded series of seven ethanol solutions. Dehydrated tissue was dried to the critical point and mounted on aluminum stubs using silver paint. Dried samples were coated with gold palladium using an Annotech Hummer VII Sputtering System (Alexandria, Va.) and observed in a Hitachi S-570 scanning electron microscope (Tokyo, Japan).

Figure 1 illustrates a shoot of $S$. bermudiana and shows its general morphology. Flowers are formed in the axils of the three

Received for publication 22 Feb. 1991. Accepted for publication 15 Aug. 1991. Reference to trade names does not imply-recommendation to the exclusion of others that may be suitable. The cost of publishing this paper was defrayed in part by the payment of page charges. Under postal regulations, this paper therefore must be hereby marked advertisement solely to indicate this fact. most distal spathe-like bracts and three flowers form in each unit. Flowers mature acropetally, from the base to the apex of the plant (Fig. 1), as well as within each floral unit (Fig. 2.4 and 2.6). Each flower consists of six tepals, three stamens, and an inferior ovary at maturity. of the axillary inflorescences; (C) fruit (capsule).
The apex is covered by an alternating series of sheathing leaves that when removed expose either the vegetative apex (Fig. 2.1) or the bract covering the floral primordium (Fig. 2.2), depending on the stage of growth.

The transition of apices from vegetative to floral occurs around the 10-week SD inductive cycle, and the floral structures become apparent at 11 weeks (Fig. 2.2). This finding is consistent with the results of the inductive cycle experiments (Roberts, 1990b). Once this initial transition occurs, development is rapid. At 11.5 weeks, common stamen-tepal primordia are apparent on the primary flower (Fig. 2.3). At 12 weeks each of these common primordia have bifurcated so that the tepals can be distinguished from the stamens (Fig. 2.5). Thus, the outer whorl of tepals (To) and the stamens develop together and are initiated before the inner whorl of tepals (Fig. 2.6, Ti). Our developmental information explains the observation by Pande and Singh (1979) that the outer tepals and the stamens share common vascular traces in the family Iridaceae. Although we could not find any recent studies of early floral develop-

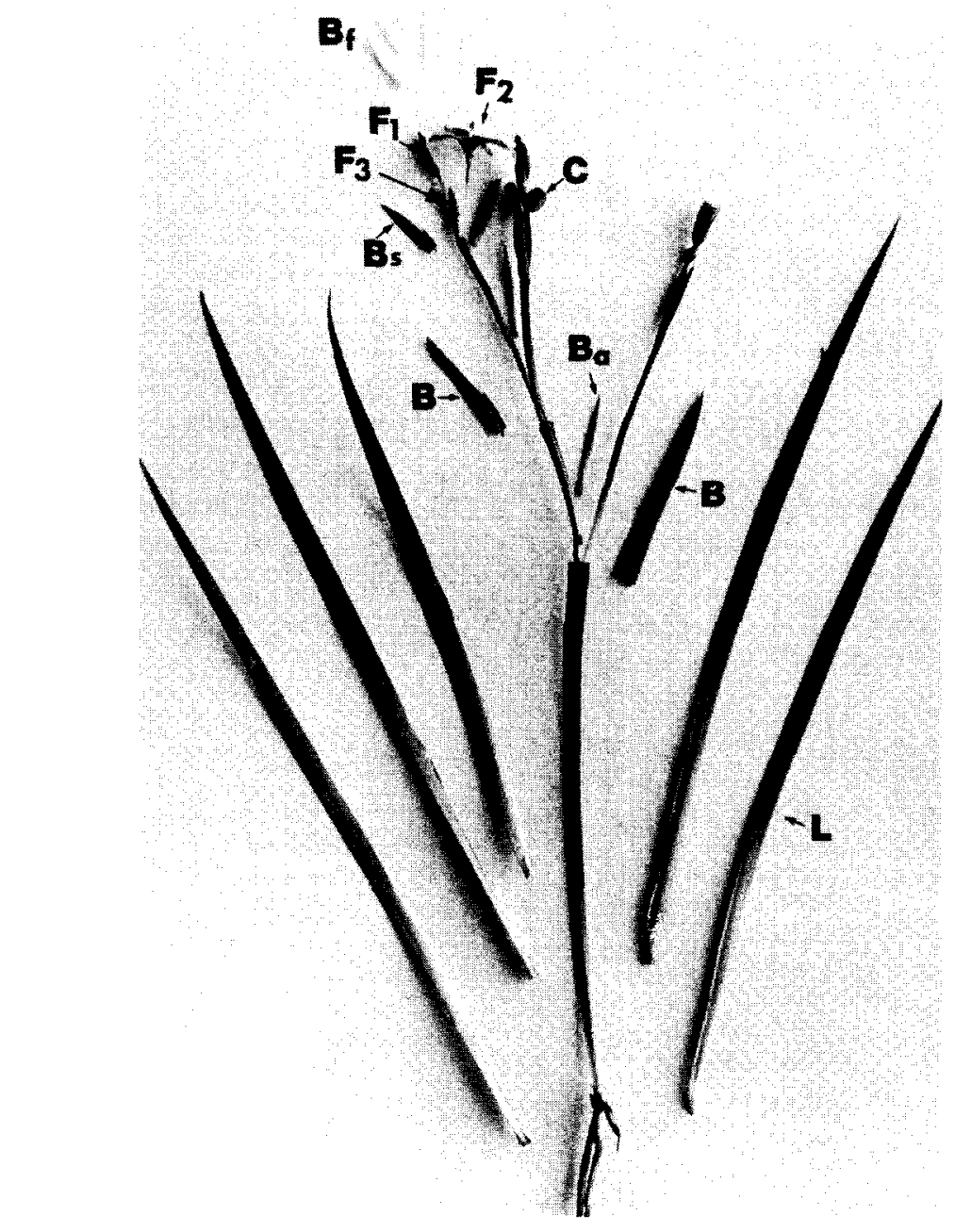

Fig. 1. Dissected Sisyrinchium bermudiana showing position of leaves, subtending bracts, and flowers. (L) leaves; F1-F3 flowers numbered youngest to oldest; (Bf) subtending bracts from the base of each flower in the terminal inflorescence; (Bs) spathe-like bracts from the base of the two primary flowers; (B) subtending bracts from the base of the two rachi; (Ba) subtending bracts from the base 


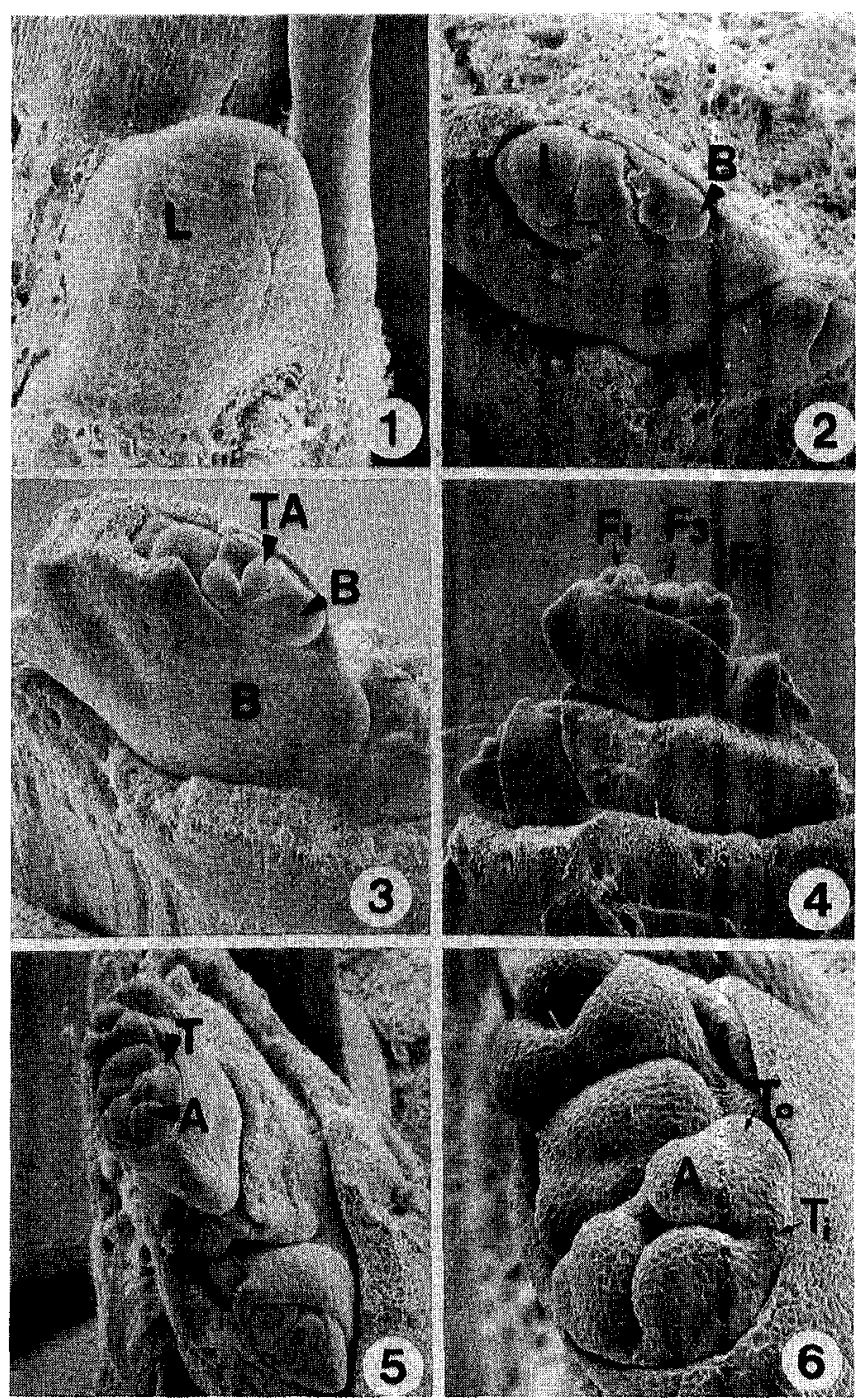

Fig. 2. Stages of floral initiation in Sisyrinchium bermudiana . (1) Vegetative apex showing leaf (L). (2) Floral apex of plant given 11 weeks of short days showing inflorescence apex (I), bract (B) $(\times 97.5)(3)$ Floral apex at 11.5 weeks of short days showing common stamen-tepal primordium (TA), bract $(B) .(\times 78)(4)$ Floral apex at 12 weeks of short days showing $F_{1}, F_{2}$, and $F_{3}$ (first, second, and third flower to develop, respectively). $(\times 65)(5)$ View of 12-week apex showing tepal $(T)$, stamen $(A) .(\times 52)(6)$ Primary flower cluster at 12 weeks showing stamen primordium $(A)$, inner tepal primordium (Ti), outer tepal primordium $(\mathrm{To}) .(\times 195)$. ment in the Iridaceae, our observations on the pattern and relative timing of organ initiation in $S$. bermudiana are the same as those made by Payer (1857) for Gladiolus communis, a member of the same family.

Observations from the scanning electron microscopy study are consistent with those of the inductive cycle experiments carried out under the same conditions (Roberts and Tsujita, 1992). Consequently, we can pinpoint floral induction microscopically to 10 weeks of SD.

\section{Literature Cited}

Hayat, M.A. 1981. Fixation for electron microscopy. Academic, New York.

Holm. T. 1908. Sisyrinchium: Anatomical studies of North American species. Bot. Gaz. 46:179195.

Pande, P.C. and V. Singh. 1979. Floral morphology of Iridaceae. Phytomorphology 29:122131.

Payer, J.B. 1857. Traité d'organogénie comparée de la fleur. Ordre des Iridées. Librairie de Victor Masson, Paris. p. 659-661.

Posluszny, U., M.G. Scott, and R. Sattler. 1980. Revisions in the technique of epi-illumination microscopy for the study of floral and vegetative apices. Can. J. Bot. 58:2491-2495.

Roberts, G.L. 1990a. Photoperiodic response of Sisyrinchium bermudiana L.-A possible new bedding plant. Acta Hort. 272:129-131.

Roberts, G.L. 1990b. Germination and flowering in Sisyrinchium bermudiana L. MS Thesis, Univ. of Guelph, Ontario, Canada.

Roberts, G.L. and M.J. Tsujita. 1992. Inductive cycles required for flowering of Sisyrinchium bermudiana. HortScience 27:80. 